\title{
Anthrax Epizootic in Wildlife, Bwabwata National Park, Namibia, 2017
}

\author{
Caitlin M. Cossaboom, Siegfried Khaiseb, \\ Bernard Haufiku, Puumue Katjiuanjo, \\ Apollinaris Kannyinga, Kaiser Mbai, \\ Thompson Shuro, Jonas Hausiku, \\ Annety Likando, Rebekka Shikesho, Kofi Nyarko, \\ Leigh Ann Miller, Simon Agolory, \\ Antonio R. Vieira, Johanna S. Salzer, \\ William A. Bower, Lindsay Campbell, \\ Cari B. Kolton, Chung Marston, Joy Gary, \\ Brigid C. Bollweg, Sherif R. Zaki, \\ Alex Hoffmaster, Henry Walke
}

In late September 2017, Bwabwata National Park in Namibia experienced a sudden die-off of hippopotamuses and Cape buffalo. A multiorganizational response was initiated, involving several ministries within Namibia and the US Centers for Disease Control and Prevention. Rapid interventions resulted in zero human or livestock cases associated with this epizootic.

\begin{abstract}
A nthrax, caused by Bacillus anthracis, is a naturally occurring zoonotic disease of veterinary and public health importance. Anthrax has been reported in wildlife and domestic animals worldwide and can spill over to humans $(1,2)$. Anthrax epizootics in hippopotamuses have been documented in several countries of southern Africa, including Zambia, Zimbabwe, and South Africa (3-5). Anthrax is also well documented in wildlife in Etosha National Park, Namibia (6). Human infections related to wildlife anthrax typically result from consumption of meat from infected carcasses, causing

Author affiliations: Centers for Disease Control and Prevention, Atlanta, Georgia, USA (C.M. Cossaboom, A.R. Vieira, J.S. Salzer, W.A. Bower, C.B. Kolton, C. Marston, J. Gary, B.C. Bollweg, S.R. Zaki, A. Hoffmaster, H. Walke); Republic of Namibia Ministry of Agriculture, Water, and Forestry, Windhoek, Namibia (S. Khaiseb, K. Mbai, T. Shuro); Republic of Namibia Ministry of Health and Social Services, Windhoek (B. Haufiku, P. Katjiuanjo, A. Likando, R. Shikesho, K. Nyarko); Republic of Namibia Ministry of Environment and Tourism, Windhoek (A. Kannyinga, J. Hausiku); Centers for Disease Control and Prevention, Windhoek (L.A. Miller, S. Agolory); University of Florida, Vero Beach, Florida, USA (L. Campbell)
\end{abstract}

DOI: https://doi.org/10.3201/eid2505.180867 ingestion anthrax, or direct contact, causing cutaneous anthrax (5). Anthrax epizootics in southern Africa are often associated with dry seasons, which typically occur during May-October $(2,7)$.

A massive dieoff of hippopotamuses and Cape buffalo began in late September 2017 along the Kavango River in Bwabwata National Park (BNP), within the Kavango East region of northeastern Namibia. We report on the multiorganizational response that addressed this event.

\section{The Study}

On September 25, 2017, Namibia's Ministry of Environment and Tourism (MET) learned of 2 hippopotamus carcasses found on the western side of BNP. During unrelated aerial surveillance in the area on October 1, MET observed 10 hippopotamus carcasses and on October 7 observed an additional 107 hippopotamus and 20 Cape buffalo carcasses. MET then notified the Ministry of Agriculture, Water, and Forestry and the Ministry of Health and Social Services (MOHSS), which together established a joint action plan. The presumptive diagnosis was anthrax based on clinical and microscopic evidence; however, culture confirmation was not initially possible because of sample collection and laboratory challenges. The US Centers for Disease Control and Prevention (CDC) was consulted for assistance with the investigation.

To address possible human exposure, MOHSS developed a questionnaire and administered it beginning on October 12 to identify persons living in communities adjacent to BNP who were exposed to the carcasses (Figure 1). In total, 1,050 persons were identified as having contact with or consuming meat from the carcasses and were immediately provided with postexposure prophylaxis (PEP) in the form of 2 weeks of ciprofloxacin and symptom monitoring (8). MOHSS returned 2 weeks later to assess PEP adherence among exposed community members and reported successful PEP adherence and no severe adverse events associated with taking PEP. Field workers performing carcass disposal continued PEP use until 2 weeks after activities concluded. MOHSS led community education to raise awareness of the ongoing outbreak, communicate the importance of not having contact with or consuming meat from animals found dead, and urge persons to seek healthcare if exposed or symptomatic. No human anthrax cases were associated with this outbreak. 


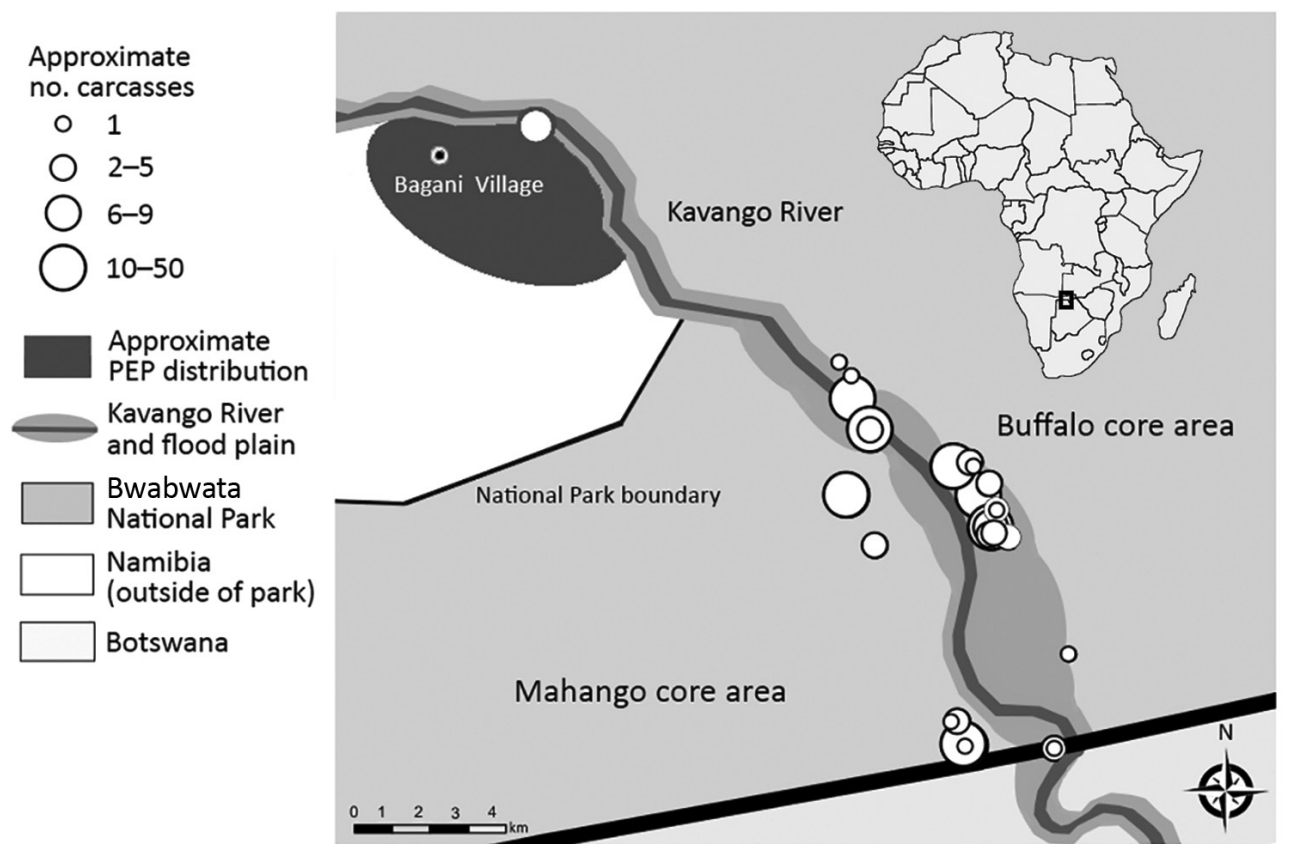

Figure 1. Anthrax investigation points of interest within and directly adjacent to Bwabwata National Park, Namibia, 2017. Inset shows location of park in Africa.

CDC developed a protocol to collect specimens from affected wildlife carcasses. A field team collected several paired samples from 7 carcasses: ear and eyelid tissue biopsy samples and swab specimens of the nasal cavity, rectum, and other pooled blood when available. We recorded geographic coordinates by using a Garmin Montana 650 GPS unit at carcass locations for eventual geospatial analysis (Figure 1).

To test samples, we used the InBios Active Anthrax Detect (AAD) Rapid Test (InBios, http://www.inbios. com), a lateral flow assay that detects capsular polypeptide of $B$. anthracis. This novel assay was developed as a point-of-care diagnostic aid for human inhalation anthrax and is available for investigational or research use only (9). A laboratory evaluation conducted on animal tissues by CDC before deployment indicated that the test had 98\% specificity and 95\% sensitivity (C.B. Kolton, unpub. data). Use of the AAD Rapid Test under field conditions is beneficial because the test requires only a small sample volume, provides results within 15 minutes, and does not require refrigeration.

We performed the AAD Rapid Test in the field on tissue and swab samples collected from wildlife carcasses, following standard protocol provided by InBios (S. Raychaudhuri, InBios, pers. comm., 2016 May 10). We suspended tissue samples in $600 \mu \mathrm{L}$ of sterile phosphate-buffered saline (PBS) and vortexed the suspension for 10 seconds. After pipetting repeatedly, we applied 10 $\mu \mathrm{L}$ to the AAD Rapid Test cassette. For swabbed exudate samples, we transferred $10 \mu \mathrm{L}$ of fluid to the cassette without PBS.
We subsequently confirmed $B$. anthracis infection by using culture, real-time reverse transcription PCR (rRTPCR), and immunohistochemistry (IHC). We processed tissue and swab samples and inoculated them into sheep blood agar or heart infusion broth, then incubated at $37^{\circ} \mathrm{C}$ for $24 \mathrm{~h}$. We performed DNA extractions on specimens by using the QIAGEN Blood Mini Kit (https://www.qiagen. com) and tested the resulting DNA by using the Laboratory Response Network's rRT-PCR for B. anthracis (10). We processed formalin-fixed tissue samples from 3 Cape buffalo and 3 hippopotamuses, embedded them in paraffin, and stained them with hematoxylin and eosin, Lillie-Twort Gram stain, and Warthin-Starry silver stain.

The vessels within the dermis of the ear biopsy in 1 Cape buffalo and ear and eyelid biopsies of 3 hippopotamuses contained large, gram-variable bacilli. We performed IHC assays using mouse monoclonal antibodies targeting the $B$. anthracis cell wall and capsule by using an immunoalkaline phosphatase polymer system, as previously described $(11,12)$, and highlighted bacterial antigen and full bacilli within the vessels of 2 buffalo and all 3 hippopotamuses (Table; Figure 2). All 6 anthrax-suspected carcasses tested positive by AAD Rapid Test and were confirmed positive for $B$. anthracis by culture, rRT-PCR, and/or IHC. A carcass of a buffalo that died from a vehicle collision was included as a negative control and tested negative by all assays (Table).

Livestock vaccination is an effective means to prevent anthrax infection in domestic animals and subsequent transmission to humans (13) and is required annually in Namibia. The Ministry of Agriculture, Water, and Forestry secured 
Table. Summary of laboratory diagnostic testing results, by carcass sampled, after an anthrax epizootic in wildlife, Bwabwata National Park, Namibia, 2017*

\begin{tabular}{|c|c|c|c|c|c|c|}
\hline \multirow[b]{2}{*}{ Carcass ID } & \multirow[b]{2}{*}{ Species } & \multirow[b]{2}{*}{ AAD Rapid Test } & \multirow[b]{2}{*}{ Culture } & \multirow[b]{2}{*}{ LRN rRT-PCR } & \multicolumn{2}{|c|}{ Immunohistochemistry } \\
\hline & & & & & Cell wall & Capsule \\
\hline 001 & Cape buffalo & + & + & $\mathrm{NA}$ & - & + \\
\hline 002 & Cape buffalo† & - & - & NA & - & - \\
\hline 005 & Cape buffalo & + & + & NA & + & + \\
\hline 007 & Hippopotamus & + & + & + & + & + \\
\hline 008 & Hippopotamus & + & - & + & + & + \\
\hline 009 & Hippopotamus & + & + & + & + & + \\
\hline 012 & Hippopotamus & + & + & + & NA & NA \\
\hline
\end{tabular}

${ }^{*}$ AAD Rapid Test, InBios Active Anthrax Detect Rapid Test (InBios, http://www.inbios.com); LRN rRT-PCR, Laboratory Response Network real-time reverse transcription PCR; NA, not available; +, positive; - , negative.

†This Cape buffalo carcass served as a negative control. The animal died as a result of a vehicle collision, and anthrax infection was not suspected as cause of death.

$\approx 10,000$ doses of livestock anthrax vaccine to prevent spillover of anthrax from wildlife into susceptible domestic animals and will enforce future annual vaccination in the affected area. MET organized vaccination of wildlife. No cases of anthrax in livestock were associated with this outbreak.

Incineration is the recommended disposal method in cases where reducing the carcass to ashes is possible to enable complete destruction of any viable spores (8). However, because of the large size and number of carcasses, burial was an alternative method of disposal. We recommended limiting the distance that carcasses were moved for burial to decrease dissemination of spores and ensuring a depth of $\geq 2 \mathrm{~m}$ was reached to prevent scavenger disruption to carcasses (1). Spraying the carcass and burial site with $10 \%$ formaldehyde minimized external contamination $(1,8)$.

By early December, the wildlife deaths subsided, and 155 hippopotamus and 86 Cape buffalo carcasses had been disposed of in the Mahango and Buffalo core areas of BNP (Figure 1). MET conducted an aerial survey in the same areas in September 2017 that recorded 588 hippopotamuses and 2,216 Cape buffalo; roughly $26.4 \%$ and $3.8 \%$ of each population were affected, respectively (14).

\section{Conclusions}

Our investigation highlights a successful public health outcome with zero human or livestock cases after an anthrax outbreak in wildlife in BNP. We demonstrated the successful use of the AAD Rapid Test for presumptive diagnosis of anthrax in wildlife under field conditions and the use of culture and IHC for confirmation of B. anthracis in hippopotamuses and Cape buffalo. The AAD Rapid Test has the potential to improve the ability of low-resource countries to quickly diagnose and effectively manage anthrax epizootics, thus reducing the risk for transmission to humans.

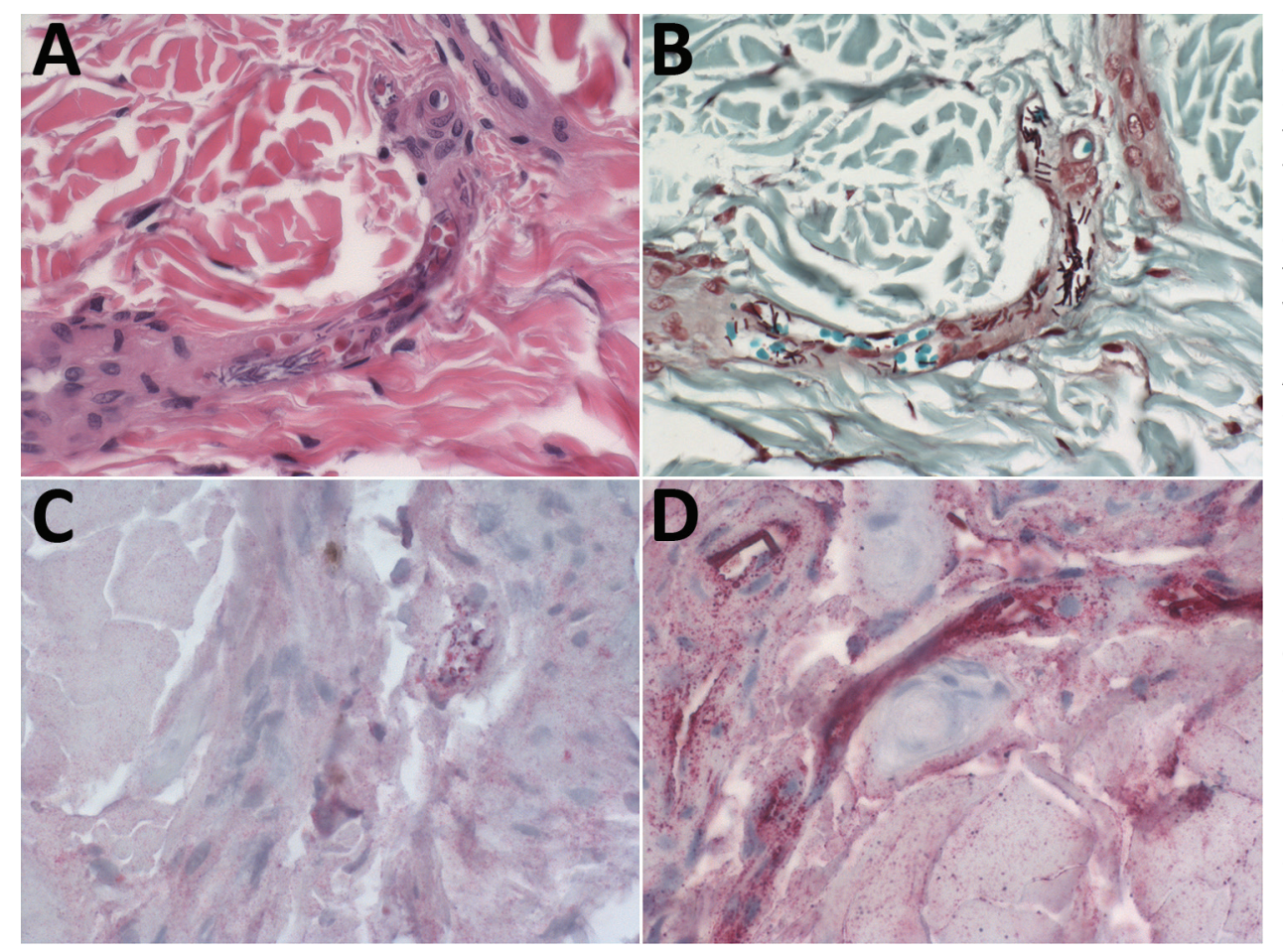

Figure 2. Photomicrographs showing hematoxylin and eosin stain and immunohistochemical findings, using assays targeting the cell wall and capsule of Bacillus anthracis, in ear-punch biopsy specimens from a hippopotamus infected with $B$. anthracis, Bwabwata National Park, Namibia, 2017. A) Hematoxylin and eosin stain showing large bacilli evident in vessel lumen. Original magnification $\times 40$. B) Gram stain showing gram-variable rods evident in vessels. Original magnification $\times 40$. C) Immunohistochemical stain of $B$. anthracis cell wall showing antigen evident in vessels (red). Original magnification $\times 40$. D) Immunohistochemical stain of $B$. anthracis capsule showing bacilli evident in vessels (red), and bacterial antigen. Original magnification $\times 63$. 
Swift response in organizing PEP dissemination, community education, livestock vaccination, and carcass disposal contributed to the prevention of anthrax transmission to humans and livestock. Our investigation emphasizes the importance of a multiagency coordinated response for zoonotic disease outbreaks and continued efforts to raise awareness of the risks of consuming meat from animal carcasses in anthrax-endemic areas.

\section{Acknowledgments}

The authors acknowledge the efforts of the Namibia Ministry of Health and Social Services, Field Epidemiology and Laboratory Training Program staff and residents, and staff of the Andara Hospital who administered questionnaires to assess exposure status, coordinated antibiotic administration, and performed follow-up assessments of exposed community members. We also acknowledge the efforts of the staff of the Namibia Ministry of Environment and Tourism, supported by the Namibia Police Air Wing and the NamParks IV Project and co-financed by the government of Namibia and KfW from the government of Germany. We acknowledge the efforts of the staff of the Namibia Ministry of Agriculture, Water, and Forestry, who performed carcass surveillance and disposal and livestock vaccination during the epizootic and months following. We also thank the staff of the Namibia Institute for Pathology in the Rundu State Hospital and Andara Hospital for providing supplies necessary to the work in the field. Finally, we thank Syamal Raychaudhuri for providing the AAD lateral flow cassettes.

\section{About the Author}

Dr. Cossaboom is an Epidemic Intelligence Service officer assigned to the Bacterial Special Pathogens Branch, Division of High-Consequence Pathogens and Pathology, National Center for Emerging and Zoonotic Infectious Diseases, Centers for Disease Control and Prevention, Atlanta, Georgia, USA. Her primary research interests include epidemiology and outbreak response of zoonotic diseases of public health importance.

\section{References}

1. Hugh-Jones ME, de Vos V. Anthrax and wildlife. Rev Sci Tech. 2002;21:359-83. http://dx.doi.org/10.20506/rst.21.2.1336

2. Munang'andu HM, Banda F, Siamudaala VM, Munyeme M, Kasanga CJ, Hamududu B. The effect of seasonal variation on anthrax epidemiology in the upper Zambezi floodplain of western Zambia. J Vet Sci. 2012;13:293-8. http://dx.doi.org/10.4142/ jvs.2012.13.3.293

3. Pienaar UD. Epidemiology of anthrax in wild animals and the control of anthrax epizootics in the Kruger National Park, South Africa. Fed Proc. 1967;26:1496-502.

4. Clegg SB, Turnbull PC, Foggin CM, Lindeque PM. Massive outbreak of anthrax in wildlife in the Malilangwe Wildlife Reserve, Zimbabwe. Vet Rec. 2007;160:113-8. http://dx.doi.org/10.1136/ vr.160.4.113

5. Lehman MW, Craig AS, Malama C, Kapina-Kany'anga M, Malenga P, Munsaka F, et al. Role of food insecurity in outbreak of anthrax infections among humans and hippopotamuses living in a game reserve area, rural Zambia. Emerg Infect Dis. 2017;23:1471-7. http://dx.doi.org/10.3201/eid2309.161597

6. Lindeque PM, Turnbull PC. Ecology and epidemiology of anthrax in the Etosha National Park, Namibia. Onderstepoort J Vet Res. 1994;61:71-83.

7. Mendelsohn J, Roberts C, Hines C. An environmental profile and atlas of Caprivi. Windhoek (Namibia): Directorate of Environmental Affairs; 1997.

8. World Health Organization. Anthrax in humans and animals. 4th ed. Geneva: The Organization; 2008. p. 84-92.

9. Gates-Hollingsworth MA, Perry MR, Chen H, Needham J, Houghton RL, Raychaudhuri S, et al. Immunoassay for capsular antigen of Bacillus anthracis enables rapid diagnosis in a rabbit model of inhalational anthrax. PLoS One. 2015;10:e126304. http://dx.doi.org/10.1371/journal.pone.0126304

10. Hoffmaster AR, Meyer RF, Bowen MD, Marston CK, Weyant RS, Thurman K, et al. Evaluation and validation of a real-time polymerase chain reaction assay for rapid identification of Bacillus anthracis. Emerg Infect Dis. 2002;8:1178-82. http://dx.doi.org/10.3201/eid0810.020393

11. Guarner J, Jernigan JA, Shieh WJ, Tatti K, Flannagan LM, Stephens DS, et al.; Inhalational Anthrax Pathology Working Group. Pathology and pathogenesis of bioterrorismrelated inhalational anthrax. Am J Pathol. 2003;163:701-9. http://dx.doi.org/10.1016/S0002-9440(10)63697-8

12. Bollweg BC, Silva-Flannery L, Spivey P, Hale GL. Optimization of commercially available Zika virus antibodies for use in a laboratory-developed immunohistochemical assay. J Pathol Clin Res. 2017;4:19-25. http://dx.doi.org/10.1002/ cjp2.84

13. Turnbull PC. Anthrax vaccines: past, present and future. Vaccine. 1991;9:533-9. http://dx.doi.org/10.1016/ 0264-410X(91)90237-Z

14. Beytell PC. Wetland survey of the Bwabwata Okavango Ramsar site, September 2017. Windhoek (Namibia): Directorate of Scientific Services; 2018.

Address for correspondence: Caitlin M. Cossaboom, Centers for Disease Control and Prevention, 1600 Clifton Rd NE, Mailstop A-30, Atlanta, GA 30329-4027, USA; email: nrm9@cdc.gov 